\title{
Fatores Antinutricionais da Casca e da Polpa Desidratada de Café (Coffea arabica L.) Armazenadas em Diferentes Períodos ${ }^{1}$
}

\section{Adauto Ferreira Barcelos ${ }^{2}$, Paulo César de Aguiar Paiva ${ }^{3}$, Juan Ramón Olalquiaga Pérez ${ }^{4}$, Vander Bruno dos Santos ${ }^{5}$, Roberto Maciel Cardoso 6}

\begin{abstract}
RESUMO - Avaliaram-se os teores de cafeína, taninos, lignina e sílica, na casca e polpa de café das cultivares Catuaí, Rubi e Mundo Novo. A polpa foi obtida pela despolpa úmida em despolpador mecânico e, em seguida, seca ao sol até 13\% de umidade. Os materiais foram armazenados em sacos de ráfia, em ambiente coberto, ventilado e seco, com amostragem em triplicata a cada 90 dias. A regressão mostrou aumento quadrático de $11,7 \%$ no teor de cafeína ao longo de 360 dias de armazenamento. O teor de taninos reduziu-se linearmente ao longo do armazenamento. Os valores de taninos foram de 1,70\% comparado a 2,77\% nos materiais sem armazenamento, redução de aproximadamente $38,6 \%$ no período de um ano. Os teores de lignina reduziram linearmente em $2,6 \%$ para a porcentagem de lignina na MS (11,7 para 11,4\%) e 5,8\% na porcentagem de lignina da FDN (10,4 para 9,8\%), nos materiais sem armazenagem comparados a doze meses de armazenamento. Houve diferença significativa entre casca e polpa para a variável sílica. Maior valor de sílica na casca comparado à polpa pode ser decorrente da presença do pergaminho, uma vez que a polpa não o possui. A armazenagem da casca e polpa por um período de doze meses melhora as qualidades destes materiais, uma vez que reduziu os teores de taninos e lignina. Os teores de cafeína encontrados são limitantes na utilização de grandes quantidades desses materiais para ruminantes.
\end{abstract}

Palavras-chave: avaliação de alimentos, alimento alternativo, resíduo agrícola, fatores antinutricionais

\section{Antinutritional Factors of the Hull and Dehydrated Pulp of Coffee (Coffea arabica L.) Stored in Different Periods}

\begin{abstract}
It was evaluated the caffeine contents of caffeine, tannins, lignin and silica in the hull and pulp of coffee of cultivars Catuaí, Rubi, Mundo Novo. Pulp was obtained by moist pulping in a mechanical pulper and dried in the sun adjusted to $13 \%$ moisture. Materials were stored in raffia bag in environment free of moisture and ventilated with samplings every 90 days. The quadratic effect shown increased caffeine content along 360 day storage, this increase was of $11,7 \%$ along 12 months. Tannin content was reduced linearly along the storage. The values of tannin were of $2.77 \%$ compared with $1.70 \%$ in the materials without storage. The reduction was of $38.6 \%$ in one year period. Lignin contents were reduced linearly in $2.6 \%$ for lignin percentage in DM (11.7 to $11.4 \%)$ and $5.8 \%$ in the lignin percentage of NDF (10.4 to $9.8 \%$ ) in the materials with no storage compared to 12-month storage. There was a significant difference between the hull and pulp for the variable silica. Increased value of silica in the hull, compared to the pulp may be due to the presence of parchment in this material, since this pulp does no possess it. The storage of hull and pulp for a 12-month period improves the qualities of these materials since it reduced tannin and lignin contents. The values of caffeine found are limiting in the use of great amounts of those materials for ruminants.
\end{abstract}

Key Words: evaluation of feed, alternative feed, agricultural residue, antinutritional factors

\section{Introdução}

A nutrição de ruminantes pode ser considerada mais complexa que a nutrição de monogástricos. Devido à anatomia do trato digestivo, os microorganismos presentes no rúmen fermentam alimentos fibrosos e sintetizam nutrientes, principalmente proteína e algumas vitaminas. Determinadas substân- cias dos alimentos podem interferir no processo, reduzindo a capacidade dos microorganismos em transformar material fibroso, em nutrientes aproveitáveis.

Sob esse aspecto, o nutricionista, ao propor sistemas de alimentação para ruminantes, deve conhecer os alimentos que utilizará, para conciliar associações ótimas para os microorganismos do rúmen. Alimentos que possuem fatores que podem interferir no proces-

\footnotetext{
${ }^{1}$ Parte da tese apresentada a Universidade Federal de Lavras - UFLA, pelo primeiro autor, para obtenção do título de Doutor em Zootecnia, na área de concentração Nutrição de Ruminantes. Projeto financiado pela FAPEMIG.

2 Pesquisador da EPAMIG/CTSM - Caixa Postal 176 - CEP 37200-000 - Lavras, MG. E.mail: barcelos@ufla.br

3 Professor titular do Departamento de Zootecnia da UFLA, bolsista do CNPQ. E.mail: pcapaiva@ufla.br

${ }^{4}$ Professor adjunto do Departamento de Zootecnia da UFLA. E.mail: jroperez@ufla.br

5 Aluno de graduação em Zootecnia na UFLA, bolsista de Iniciação Científica do PIBIC/CNPq

6 Professor Aposentado da Universidade Federal de Viçosa-UFV/CCA/DZO.
} 
so fermentativo devem ser utilizados com cautela ou restrição, para não afetar o metabolismo ruminal.

A casca e a polpa de café têm sido recomendadas e utilizadas na alimentação de ruminantes, até $30 \%$ no concentrado de vacas em lactação e $40 \%$ no concentrado de novilhos confinados. Pesquisas para buscar formas de utilização desses materiais devem-se basicamente à sua grande disponibilidade nas regiões cafeeiras.

Atualmente, com a maior cotação no mercado internacional do café de melhor qualidade, a despolpa tem sido empregada para produzir café de alto padrão. Esse processo gera a polpa, que tem tornado um problema para o cafeicultor, uma vez que pode ser poluente ao meio ambiente. Alternativas de utilização para este material são responsabilidade das instituições de pesquisa agropecuária.

Estudar detalhadamente a casca e a polpa desidratada de café definirá se é possível sua utilização na alimentação de ruminantes.

A polpa de café úmida e desidratada foi estudada em países da América Latina por JIMÉNEZ et al. (1970); BRESSANI, ESTRADA e JARQUIN (1972); JARQUIN et al. (1973); CABEZAS et al. (1974); CABEZAS, GONZALES e BRESSANI (1974); MOLINA, FLUENTE e BRESSANI (1974); JARQUIN, MURILLO e GONZALES (1974); MURILLO, CABEZAS e BRESSANI (1975); RECINOS (1976); CABEZAS (1976); VARGAS, CABEZAS e BRESSANI (1977a); VARGAS, CABEZAS e BRESSANI (1977b); RUIZ e RUIZ (1977); BRAHAM et al. (1977); MURILLO et al. (1977) e VARGAS et al. (1982). Esses estudos indicam a presença de alguns componentes que interferem na utilização da polpa como alimento para ruminantes. Compostos como cafeína e taninos têm sido indicados como possíveis fatores antinutricionais da polpa, mas sem evidências conclusivas que apóiem esta afirmativa (RAMIREZ-MARTINEZ, 1988).

BARCELOS et al. (1997a) e BARCELOS et al. (1997b) encontraram teores de 1,83 e 1,29\% de taninos e 0,86 e $0,81 \%$ de cafeína, enquanto Ribeiro Filho (1998) encontrou teor de 2,08\% para os compostos fenólicos totais da casca de café e $0,97 \%$ para cafeína.

Segundo RAMIREZ (1987), os compostos fenólicos, ou polifenóis, estão presentes nos vegetais e compreendem um grupo heterogêneo de substâncias, umas com estruturas químicas relativamente simples e outras complexas como os taninos e a lignina. $\mathrm{O}$ grão do fruto do café da espécie Coffea arabica L. caracteriza-se pelo alto conteúdo desses compostos e, em particular, dos chamados ácidos clorogênicos.
O conteúdo de fenólicos nas paredes primárias da célula é baixo e, nas monocotiledôneas, consiste em grande parte em monômeros de ácidos fenólicos, aldeídos e polímeros fenólicos de baixo peso molecular (CHESSON e FORSBERG, 1988). Os ácidos fenólicos podem ser encontrados na parede secundária de gramíneas, em aproximadamente $1 \%$ da MS, sendo a lignina o material fenólico de maior teor presente na parede secundária.

Existe evidência de que alguns monômeros fenólicos, liberados durante a degradação microbiana de materiais fibrosos das plantas, podem inibir o crescimento de certas bactérias do rúmen e deprimir a digestão da celulose (CHESSON, STEWART e WALLACE, 1982; JUNG, FAHEY e GARST, 1983 e JUNG, 1985). Segundo DAWSON e ALLISON (1988), os compostos fenólicos, que influenciam a digestão da celulose, incluem ácidos benzóico, cinâmico e caféico.

ØRSKOV (1992) afirma que plantas que contêm alta proporção de tanino podem ser resistentes à degradação no rúmen. $\mathrm{O}$ tanino parece causar ligação cruzada entre proteínas e outras moléculas. Assim, o tanino pode ser utilizado como método de proteção, na degradação da proteína no rúmen. Há aparentemente dois tipos de reações com o tanino: uma reação de hidrolise, que é reversível em condições ácidas no abomaso e outra reação de condensação, a qual é irreversível.

VARGAS et al. (1982) ao estudarem o efeito da cafeína e taninos presentes na polpa desidratada de café, sobre o comportamento de novilhos, encontraram que ambas as substâncias afetam o consumo de matéria seca e o ganho de peso. Os valores que relacionam o consumo de cafeína e de taninos em g/ $100 \mathrm{~kg}$ de peso vivo/dia com o de MS por $100 \mathrm{~kg}$ de peso/dia podem ser obtidos pelas equações apresentadas a seguir. Uma delas é $\mathrm{Y}=4,2031-0,1819 \mathrm{x}$ com $\mathrm{r}=0,90$, em que $\mathrm{Y}$ representa o consumo de MS e $\mathrm{x}$ o consumo de cafeína. A outra é $Y=4,2177-0,030 x$ e $\mathrm{R}=0,91$ em que $\mathrm{x}$ é o consumo de taninos. Também mostram uma relação entre o consumo de taninos e de cafeína, expressa pela equação $\mathrm{Y}=0,1765+$ $6,1371 \mathrm{x}$ em que $\mathrm{Y}$ representa o consumo de taninos em $\mathrm{g} / 100 \mathrm{~kg}$ de peso vivo/dia e x o consumo de cafeína nestas mesmas unidades.

O objetivo deste trabalho foi avaliar na casca e polpa desidratadas de três cultivares de café, armazenadas por um período de doze meses, os teores de fatores antinutricionais, visando sua recomendação na alimentação de ruminantes. 


\section{Material e Métodos}

O experimento foi conduzido no Laboratório de Nutrição Animal do Departamento de Zootecnia da Universidade Federal de Lavras e Laboratório de Qualidade do Café Dr. Alcides de Carvalho do CTSM, da EPAMIG, no município de Lavras, no período de outubro de 1997 a dezembro de 1998.

Utilizou-se casca e polpa desidratada de três cultivares de café (Catuaí, Rubi e Mundo Novo) provenientes da Fazenda Experimental de São Sebastião do Paraíso, da EPAMIG.

A casca foi obtida, após a secagem dos grãos ao sol, da limpeza do café em coco por cultivar; e a polpa foi obtida também por cultivar, pela despolpa úmida, utilizando-se de despolpador DC3 e degomado no degomador mecânico DM2, ambos Pinhalense ${ }^{\circledR}$ e, em seguida, seca ao sol até $13 \%$ de umidade.

Tanto a casca quanto a polpa foram armazenadas em sacos de ráfia, em ambiente coberto, ventilado e seco, por um ano. Neste período, foram coletadas a cada 90 dias amostras em triplicata para análises bromatológicas.

Determinaram-se, na casca e na polpa desidratada, os teores de cafeína e taninos, segundo metodologia do ASSOCIATION OF OFFICIAL ANALYTICAL CHEMISTS - AOAC (1990), lignina e sílica, segundo metodologia descrita em SILVA (1981).

As amostras foram pré-secas em estufa a $65^{\circ} \mathrm{C} \mathrm{com}$ ventilação até alcançar peso constante, o que ocorreu entre 36 e 48 horas e moídas em peneira de $2 \mathrm{~mm}$.

$\mathrm{O}$ delineamento experimental foi inteiramente casualizado com três repetições em esquema fatorial $3 \times 2 \times 5$ (cultivar $\times$ material $\times$ armazenamento), onde as cultivares foram: Catuaí vermelho IAC2077-2-5-99, Rubi MG1192 e Mundo Novo IAC379-19, o material: casca e polpa desidratada e o armazenamento 0, 90, 180, 270, e 360 dias, conforme modelo estatístico:

$$
Y_{i j k l}=\mu+C_{i}+M_{j}+P_{k}+C M_{i j}+C P_{i k}+M P_{j k}+C M P_{i j k}+e_{i j k l}
$$
em que: $\mu=$ média geral; $\mathrm{Yi}_{\mathrm{jkl}}=$ observação referente a cultivar $\mathrm{i}$ do material $\mathrm{j}$ no tempo $\mathrm{k}$ e repetição 1 ; $\mathrm{C}_{\mathrm{i}}=$ efeito da variedade, sendo $\mathrm{i}=1 \mathrm{a} 3 ; \mathrm{M}_{\mathrm{j}}=$ efeito de material, sendo $\mathrm{j}=1 \mathrm{a} 2 ; \mathrm{P}_{\mathrm{k}}=$ efeito do período de armazenamento, sendo $\mathrm{k}=1$ a $5 ; \mathrm{CM}_{\mathrm{ij}}=$ efeito da interação de cultivar i e material $\mathrm{j} ; \mathrm{CP}_{\mathrm{jk}}=$ efeito da interação cultivar i e período de armazenamento $\mathrm{k} ; \mathrm{MP}_{\mathrm{jk}}=$ efeito da interação material $\mathrm{j}$ e período de armazenamento $\mathrm{k}$; $\mathrm{CMP}_{\mathrm{ijk}}=$ efeito da interação cultivar $\mathrm{i}$, material $\mathrm{j}$ e período de armazenamento $\mathrm{k}$; $\mathrm{e}_{\mathrm{ijk}}=$ erro aleatório associado a cada observação.
Os dados foram analisados utilizando-se pacote estatístico Sistema de Análise de Variância para Dados Balanceados - Sisvar, segundo FERREIRA (2000) e as médias comparadas pelo teste de SCOTT e KNOTT (1974).

\section{Resultados e Discussão}

Os teores de cafeína encontrados neste estudo estão de acordo com os mínimos $(0,48 \%)$ e máximos $(1,31 \%)$ encontrados na literatura (BRESSANI, ESTRADA e JARQUIN, 1972; JARQUIN et al., 1973; VARGAS et al., 1982; Ramirez-Martinez, 1988) Também estão próximos aos de BARCELOS et al. (1997a) e BARCELOS et al. (1997b) para a casca de café, que foram, respectivamente, de 0,86 e $0,81 \%$ na MS.

Pela análise estatística não foram verificados efeitos de cultivares $(P \geq 0,94)$ e de material $(P \geq 0,73)$, indicando que tanto a casca $(0,87 \%)$ quanto a polpa $(0,86 \%)$ e as cultivares Catuaí $(0,87 \%)$, Rubi $(0,87 \%)$ e Mundo Novo $(0,86 \%)$ apresentaram teores de cafeína semelhantes (Tabela 1).

Embora a análise estatística tenha encontrado efeito significativo para o período de armazenamento, o aumento no teor de cafeína foi de $0,83 \mathrm{sem}$ armazenamento para $0,94 \%$ com armazenagem de 12 meses, representando aumento de $11,7 \%$. O tempo de armazenamento neste estudo foi menor que o de BRESSANI et al. (1977). Não foi possível estabelecer uma explicação biológica para este fato. O mais provável é que houve alteração na proporção de componentes, uma vez que os dados estão expressos em \% na MS. Diminuição de outros componentes fenólicos como taninos e lignina pode levar à maior estimativa da cafeína.

Tabela 1 - Teores médios de cafeína da casca e polpa das cultivares de café, em \% na MS

Table 1 - Average caffeine contents of coffee peel and pulp, $\%$ in $D M$

\begin{tabular}{llcc}
\hline Material & \multicolumn{2}{c}{$\begin{array}{l}\text { Teor de cafeína (\% na MS) } \\
\text { Caffeine content }(\% \text { in DM) }\end{array}$} & \\
\cline { 2 - 3 } & Casca & Polpa & Média \\
& Hull & Pulp & Mean \\
\hline Catuaí & 0,87 & 0,87 & 0,87 \\
Rubi & 0,88 & 0,86 & 0,87 \\
Mundo Novo & 0,86 & 0,87 & 0,87 \\
\hline Média & 0,87 & 0,87 & 0,87 \\
Mean & & & \\
\hline CV $(\%)$ & & 8,89 & \\
\hline
\end{tabular}


1328

Tabela 2 - Teores médios de cafeína da casca e polpa de café das cultivares por período de armazenamento, em \% da MS

Table 2 - Average caffeine contents of coffee peel and pulp, by stored period, in \% DM

\begin{tabular}{lccccc}
\hline Cultivar & \multicolumn{5}{c}{$\begin{array}{c}\text { Período de armazenamento (dias) } \\
\text { Cultivar }\end{array}$} \\
\cline { 2 - 6 } & 0 & 90 & 180 & 270 & 360 \\
\hline Catuai & 0,79 & 0,89 & 0,85 & 0,85 & 0,96 \\
Rubi & 0,87 & 0,86 & 0,85 & 0,87 & 0,94 \\
Mundo Novo & 0,87 & 0,76 & 0,86 & 0,92 & 0,92 \\
\hline CV $(\%)$ & \multicolumn{5}{c}{8,89} \\
\hline
\end{tabular}

Tabela 3 - Teores médios de sílica na casca e polpa das cultivares de café, em \% na MS

Table 3 - Average silica contents iof coffee peel and pulp, in \% $D M$

\begin{tabular}{lc}
\hline $\begin{array}{l}\text { Material } \\
\text { Material }\end{array}$ & $\begin{array}{r}\text { Sílica (\% na MS) } \\
\text { Silica }(\% \text { in DM) }\end{array}$ \\
\hline Casca & $1,71 \mathrm{a}$ \\
Hull & $1,57 \mathrm{~b}$ \\
Polpa & \\
Pulp & 14,07 \\
\hline CV $(\%)$ & \\
\hline
\end{tabular}

Médias seguidas de letras diferentes são diferentes pelo teste t a $5 \%$ de probabilidade.

Means followed by different letters are different by $t$ test at $5 \%$ of probability.

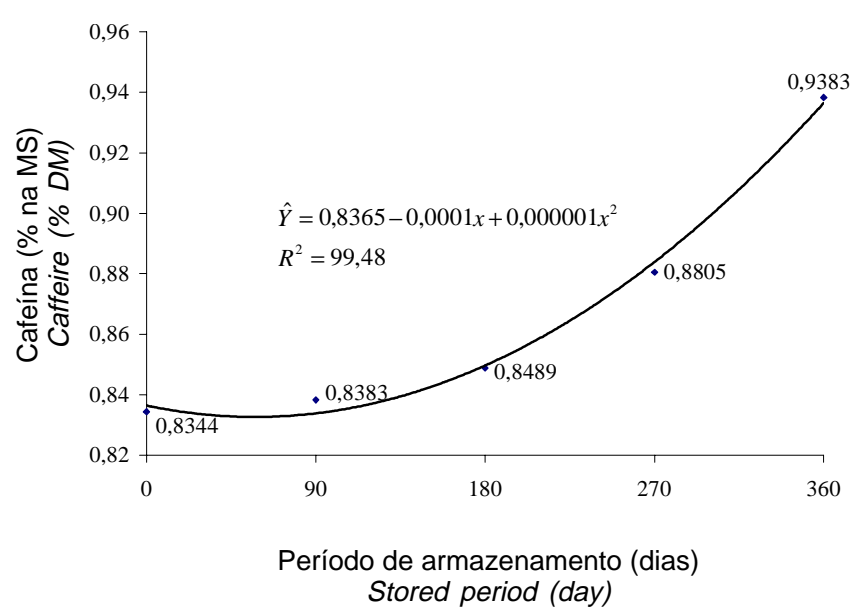

Figura 1 - Efeito do período de armazenamento nos teores médios de cafeína, da casca e polpa de café, em $\%$ na MS.

Figure 1 - Effect of the storage period on the average caffeine contents, of the hull and pulp of coffee, $\%$ in the DM.
O período de armazenamento influenciou $(\mathrm{P} \leq 0,001)$ o teor de cafeína da casca e polpa desidratada das três cultivares (Figura 1). O efeito quadrático indica aumento no teor de cafeína ao longo de 360 dias de armazenamento. Este resultado diverge dos de BRESSANI et al. (1977), os quais afirmam que o armazenamento da polpa de café desidratada por 17 meses reduziu o teor de cafeína de 0,90 para $0,46 \%$.

A análise estatística não encontrou efeito de cultivares, material e nas interações no teor de taninos. No entanto, o efeito de período de armazenamento sobre o teor de taninos foi significativo ( $\mathrm{P} \leq 0,001)$, apresentando redução linear ao longo dos 12 meses de armazenamento (Figura 2). Os valores de taninos foram, ao final de 12 meses, de 1,70\% comparado a 2,77\% nos materiais sem armazenamento. Esta redução foi de aproximadamente $38,6 \%$ no período de um ano.

Não foi encontrada na literatura informação sobre a variação nos teores de taninos na casca e polpa desidratada de café, em relação ao tempo de armazenamento.

De acordo com CABEZAS (1976), a concentração de taninos e cafeína, em níveis acima de $0,75 \%$ e $0,12 \%$ na MS, respectivamente, na dieta de bovinos, afeta o consumo e a utilização do alimento pelos animais. Trabalhos de BARCELOS et al. (1997a), BARCELOS et al. (1997b), RIBEIRO FILHO (1998) e VILELA (1999) mostraram não haver redução no

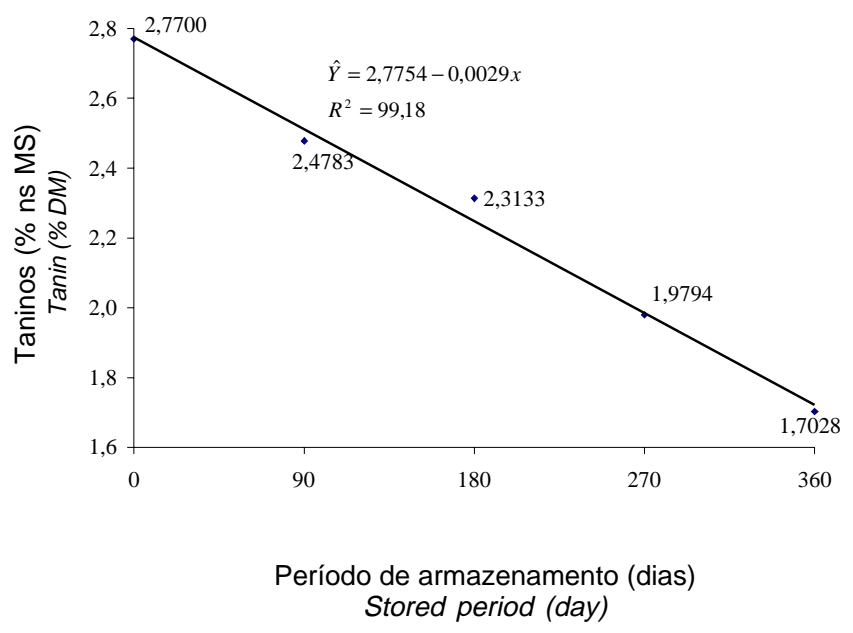

Figura 2 - Efeito do período de armazenamento nos teores médios de taninos da casca e polpa de café, em $\%$ na MS.

Figure 2 - Effect of the storage period on the average tannin contents, of the hull and pulp of coffee, $\%$ in the DM. 
Rev. bras. zootec.

consumo de MS, à medida que aumentou a quantidade de casca de café no concentrado de novilhos confinados até o nível de 40\% (16\% na MS da dieta), correspondendo a um consumo de $0,15 \%$ de cafeína e $0,33 \%$ de taninos provenientes da casca.

Alguns monômeros fenólicos liberados durante a degradação microbiana da fibra das plantas inibem o crescimento das bactérias celulolíticas do rúmen, deprimindo a digestão da celulose (CHESSON, STEWART, WALLACE 1982; JUNG, FAHEY e GARST, 1983; JUNG, 1985). Entre os compostos fenólicos que afetam a digestão da celulose, incluem-se ácidos benzóico, cinamico e caféico (DAWSSON e ALLISSON, 1988).

Plantas que contêm alta proporção de tanino são relativamente resistentes à degradação no rúmen; o tanino causa ligação cruzada entre proteínas e outras moléculas, podendo ser reversível em meio ácido ou irreversível se a reação for de condensação (ØRSKOV, 1992). Se a ação dos taninos da casca e polpa desidratada de café for do tipo reversível em meio ácido, quando a digesta chegar ao abomaso, onde o meio é ácido, o processo poderá ser revertido e os nutrientes complexados ficarão disponíveis para absorção. Considerando esse fato, serão necessários maiores estudos, a fim de caracterizar os compostos fenólicos presentes na casca e polpa de café, para identificar em que grupo se enquadram.

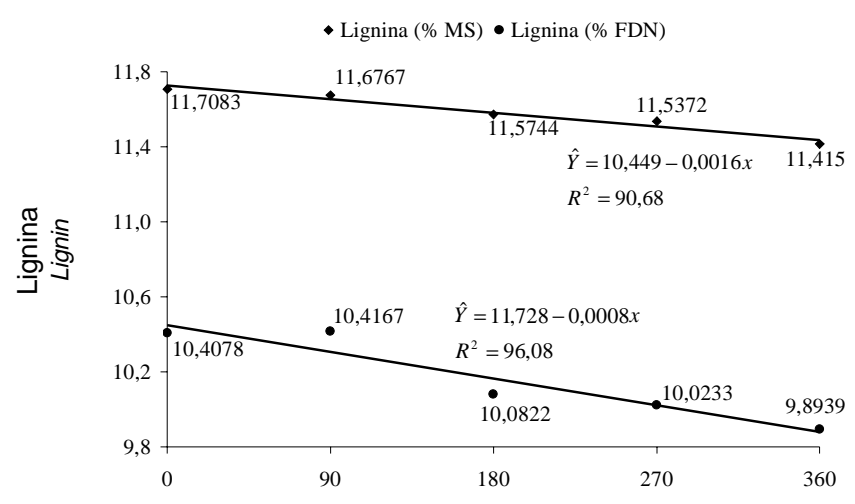

Período de armazenamento (dias) Storage period (days)

Figura 3 - Efeito do período de armazenamento nos teores médios de lignina na casca e polpa de café, em $\%$ na MS e na FDN.

Figure 3 - Effect of the storage period on the average lignin contents, of the hull and pulp of coffee, \% in DM and NDF.
1329

Os teores mínimos e máximos de lignina encontrados neste estudo estão dentro do intervalo dos valores apresentados na literatura, que são de 9,3 a $13,5 \%$ para casca e polpa de café, em \% na MS (RIBEIRO FILHO, 1998). Por outro lado, são inferiores aos teores das gramíneas e superiores aos das leguminosas tropicais apresentados por SILVA (1981).

Os teores médios de lignina na MS e FDN foram influenciados $(\mathrm{P} \leq 0,02)$ pelo período de armazenamento. Não havendo diferença significativa ( $P \geq 0,05)$ entre os teores médios das cultivares e dos materiais.

Ao longo dos doze meses de armazenamento, os teores de lignina (em \% na MS e \% da FDN) reduziramse linearmente (Figura 3). A diminuição foi de 2,6\%, na MS $(11,7$ para $11,4 \%)$ e de 5,8\% na FDN $(10,4$ para 9,8\%) entre oinício e após doze meses de armazenamento.

Conforme descrito por CHESSON e FORSBERG (1988), a lignina, a substância fenólica de maior participação nas paredes celulares secundárias, é formada quando seus precursores, p-cumaril, coniferil e álcoóis sinapil, são liberados na parede celular e são polimerisados in situ para formar a estrutura tridimensional da molécula. Esse processo de lignificação dos polissacarídeos da parede, basicamente de celulose, indisponibilizará a celulose para os microorganismos do rúmen.

Segundo CHESSON e FORSBERG (1988), a porosidade da parede lignificada é insuficiente para permitir a difusão livre das enzimas, principalmente as celulolíticas, restringindo o ataque das enzimas ao exterior ou interior da superfície celular. Elevado teor de lignina em alimentos utilizados na nutrição de ruminantes indica paredes celulares com carboidratos indisponíveis para as bactérias ruminais.

A analise de variância mostrou efeito do tipo de resíduo $(\mathrm{P} \leq 0,001)$, casca e polpa desidratada, nos teores de sílica. Entretanto, não foi observado efeito significativo de cultivares e período de armazenamento para a mesma variável.

Maior teor de sílica na casca, comparado à polpa (Tabela 3), pode ser decorrente da presença do pergaminho neste material, mas não na polpa. O pergaminho é a fração anatômica que recobre o endosperma do grão, com função de proteção da semente (JARQUIN, MURILO e GONZALES, 1974). No pergaminho encontra-se alta concentração de sílica, o que proporcionou maior teor para a casca.

TEIXEIRA (1999) encontrou baixa degradabilidade potencial e efetiva no pergaminho, indicando que esta fração é de baixo aproveitamento pelos microorganismos ruminais, devido ao alto teor de material lignificado. 
Segundo VAN SOEST (1994), a sílica é depositada nos pêlos superficiais da planta e bordas cuticulares como mecanismo de defesa em certas plantas. Em outras plantas, é um elemento estrutural complementando a lignina para fortalecer e enrijecer a parede celular. Isto influencia o metabolismo de carboidratos, promovendo a redução dos conteúdos de proteína e lignina.

Estudos in vitro têm mostrado que a sílica reduz diretamente a digestibilidade da parede celular (HARTLEY, 1981; SHIMOJO e GOTO, 1989 e VAN SOEST, 1981), no entanto, é relativamente solúvel em condições ruminais, podendo ser absorvida pelo animal e excretada na urina (VAN SOEST, 1994). Os teores valores de sílica encontrados, embora baixos, se comparados a outros componentes da casca e polpa desidratada como lignina, cafeína e taninos, poderão interferir na utilização de alguns alimentos pelos ruminantes.

\section{Conclusões}

Os teores de cafeína, taninos e lignina foram semelhantes, na casca e polpa desidratada nas cultivares de café Catuaí, Rubi e Mundo Novo.

Os teores de sílica foram semelhantes entre as três cultivares, não se alterando com o período de armazenamento.

O armazenamento por um período de doze meses melhora a qualidade da casca e polpa desidratada de café, uma vez que reduz os teores de taninos e lignina, os quais interferem no seu aproveitamento pelos ruminantes. Por outro lado, a concentração de cafeína aumentou com o tempo de armazenagem, e pode ser limitante na utilização do material.

\section{Referências Bibliográficas}

ASSOCIATION OF OFFICIAL ANALYTICAL CHEMISTS AOAC. 1990. Official methods of analysis. 15.ed. Washington.

BARCELOS, A.F., ANDRADE, I.F., TIESENHAUSEN, I.M.E.V. Von 1997a. Aproveitamento da casca de café na alimentação de novilhos confinados. I - Resultados do primeiro ano. R. Bras. Zootec., 26(6):1208-1214.

BARCELOS, A.F., ANDRADE, I.F., TIESENHAUSEN, I.M.E.V. Von 1997b. Aproveitamento da casca de café na alimentação de novilhos confinados. I - Resultados do segundo ano. R. Bras. Zootec., 26(6):1215-1221.

BRAHAM, J.E., JARQUIN, R., GONZALEZ, J.M., BRESSANI, R. 1977. Pulpa e pergamino de café - Utilización de la pulpa de café en forma de ensilage. Revista Cafetalera, 164:25-34

BRESSANI, R., ESTRADA, E., ELIAS, L.G., JARQUIN, R., VALLE, L.U. de. 1977. Pulpa y pergamino de café. Efecto de la pulpa de café deshidratada en la dieta de ratas e pollos. Revista Cafetalera, 164:35-44.

BRESANI, R., ESTRADA, E., JARQUIN, R. 1972. Pulpa e pergamino de café. I. Composición química y contenido de aminoácidos de la proteína de la pulpa. Turrialba, 22(3):299-304.

CABEZAS, M.T. 1976. Valor nutritivo de la pulpa de café para ganado de carne. Agricultua en El Salvador, 15(3):25-39.

CABEZAS, M.T., GONZALEZ, J.M., BRESSANI, R. 1974. Pulpa e pargamino de café. V. Absorción y retención de nitrógeno en terneros alimentados com raciones elaboradas con pulpa de café. Turrialba, 24(1):90-94.

CABEZAS, M.T., JARQUIN, R., GONZALES, J.M. 1974. Pulpa e pergamino de café. VI. Adaptación del ganado bovino a la pulpa de café. Turrialba, 24(2):161-167.

CHESSON, A., FORSBERG, C.W. 1988. Polysaccharide degradation by rumen microorganisms. In: HOBSON, P.N. (Ed.) The rumen microbial ecosystem. London: Elsevier Applied Science. p.251-284.

CHESSON, A., STEWART, C.S., WALLACE, R.J. 1982. Influence of plant phenolic acids on growth and cellulolytic activity of rumen bacteria. Applied Environmental Microbiology, 44(3):597-603.

DAWSON, K.A., ALLISON, M.J. Digestive disorders and nutritional toxicity. In: HOBSON, P.N. (Ed.) The rumen microbial ecosystem. London: Elsevier Applied Science, 1988. p.445-459.

FERREIRA, D.F. Análises estatísticas por meio do Sisvar para Windows versão 4.0. In... REUNIÃO ANUAL DA REGIÃO BRASILEIRA DA SOCIEDADE INTERNACIONAL DE BIOMETRIA, 45, 2000. Anais... São Carlos, SP: SIB, 2000. p. 255-258.

HARTLEY, R.D. 1981. Chemical constitution, properties and processing of lignocellulosic wastes in relation to nutritional quality for animals. Agricultural Enviromental, 6:87-96.

JARQUIN, R., JORGE, M.G., BRAHAM, J.E. et al. 1973. Pulpa y pergamino de café. II. Utilización de la pulpa de café en la alimentación de rumiantes. Turrialba, 33(1):41-47

JARQUIN, R., MURILLO, B., GONZALES, J.M. 1974. Pulpa e pergamino de café. VII. Utilización de pergamino de café en la alimentación de rumiantes. Turrialba, 24(2):168-172.

JIMÉNEZ, F.L.O., QUITEÑO R.A., MARTÍNEZ, R.A., RODRÍGUEZ. M. 1970. Uso de pulpa de café seca en el engorde de novilhos en confinamiento. Agricultura en El Salvador, 10(1):3-9.

JUNG, H.G. 1985. Inhibition of structural carbohydrate fermentation by forage phenolics. J. Sci. Food Agric., 36(2):74-80.

JUNG, H.G., FAHEY, G.C., GARST, J.E. 1983. Simple phenolic monomers of forage and effects of in vitro fermentation on cell wall phenolics. J. Anim. Sci., 57(5):1294-1305.

MOLINA, M.R., FLUENTE, G., BRESSANI R. 1974. Pulpa e pergamino de café. VIII. Estudios básicos sobre la deshidratación de la pulpa de café. Turrialba, 24(3):280-284.

MURILLO, B., CABEZAS, M.T., BRESSANI, R. 1975. Pulpa e pergamino de café. X. Cambios en la composición química del pergamino de café por efecto de diferentes tratamientos alcalinos, Turrialba, 25(2):79-182.

MURILLO, B., CABEZAS, M.T., JARQUIN, R., BRESSANI, R. 1977. Effecto of bissulfite addition on the chemical composition and cellular content fractions of dehydrated coffee pulp. J. Agric. and Food Chemistry, 25(5):1090-1092.

ØRSKOV, E.R. 1992. Protein nutrition in ruminants. 2.ed. London: Academic Press. 175p.

RAMIREZ, J. 1987. Compuestos fenólicos em la pulpa de café. Cromatografia de papel de pulpa fresca de 12 cultivares de 
Rev. bras. zootec.

Caffea arabica L. Turrialba, 37(4):317-323.

RAMIREZ-MARTINEZ, J.R. 1988. Phenolic compounds in coffee pulp: Quantitative determination by HPLC. Journal of the Science of Food Agriculture, 43(2):135-144.

RECINOS, F.F. 1976. Pulpa de café en la alimentación de bovinos. Agricultura en El Salvador, 15(3):3-10.

RIBEIRO FILHO, E. Degradabilidade in situ da matéria seca, proteína bruta e da fibra em detergente neutro da casca de café e desempenho de novilhos mestiços em fase de recria. Lavras: UFLA, 1998. 55p. (Mestrado em Zootecnia) - Universidade Federal de Lavras.

RUIZ, M.E., RUIZ, A. 1977. Efecto del consumo de pasto verde sobre el consumo de pulpa de café y la ganancia de peso en novillos. Turrialba, 27(1):23-28.

SCOTT, A.J., KNOTT, M. 1974. A Cluster analysis method for grouping means in the analysis of variance. Biometrics, 30:507-512.

SHIMOJO, M., GOTO, I. 1989. Effects of sodium silicate on forage digestion with rumen fluid of goats or cellulase using culture solutions adjusted for pH. Anim. Feed Sci. Techn., 24:173-177.

SILVA, D.J. 1981. Análise de alimentos - métodos químicos e biológicos. Viçosa, MG: UFV. 166p.

SMITH, G.S., NELSON, A.B. 1975. Effects of sodium silicate added to rumen cultures on forage digestion with interactions of glucose, urea and minerals. J. Anim. Sci., 41(3):890-899.

TEIXEIRA, M.N.M. Determinação da degradabilidade in situ das diferentes frações da casca de três cultivares de café (Coffea arabica L.). Lavras: UFLA, 1999. 44p. Dissertação (Mestrado em Zootecnia) - Universidade Federal de Lavras, 1999.

VAN SOEST, P.J. 1981. Limiting factors in plant residues o low biodegradability. Agricultural Environment, 6:135-143.
VAN SOEST, P.J. Nutritional ecology of the ruminant. 2.ed. Cornell University Press, 1994. 476p.

VARGAS. E., CABEZAS, M.T., BRESSANI, R. 1977a. Pulpa de café en la alimentación de rumiantes. II. Absorción e retención de nitrógeno en novillos alimentados com concentrados elaborados com pulpa de café deshidratada. Agronomia Costarricense, 1(2):101-106.

VARGAS, E., CABEZAS. M.T., BRESSANI, R. 1977b. Pulpa de café en la alimentación de rumiantes. I. Digestibilidade in vivo de la pulpa. Agronomia Costarricense, 1(2):51-56.

VARGAS, E., CABEZAS, M.T., MURILLO, B., BRAHAM, E.J., BRESSANI, R. 1982. Effecto de altos niveles de pulpa de café deshidratada sobre el crescimento y adaptación de novillos jovenes. Archivos Latinoamericanos de Nutricion, 32(4):972-989.

VILELA, F.G. Uso da casca de café melosa em diferentes níveis na alimentação de novilhos confinados. Lavras: UFLA, 1999. 46p. Dissertação (Mestrado em Zootecnia) - Universidade Federal de Lavras, 1999.

Recebido em: $15 / 12 / 00$

Aceito em: 26/03/01 